\title{
Influence of Conflict Management on Improved Personnel Performance in the Bank of Industry and Mining
}

Amir Hossein Amirkhani

Management Group,Payame Noor University, Varamin, Iran

Ali Farahani, PhD Student

Behavioral Management, College of Management, University of Kharazmi, Tehran, Iran

Amir Farahani, BS Student

Information Technology Engineering, Azad Islamic University, Ashtian, Iran

Doi:10.5901/mjss.2016.v7n2s2p43

\begin{abstract}
This research sought to evaluate the influence of conflict management on improved performance of personnel at the Bank of Industry and Mining. Statistical population under study consisted of employees of the Bank of Industry and Mining of Tehran where 100 individuals among them were selected as statistical sample for participation in the study. This was a field study were by use of the survey method, questionnaire was used for data collection. Ultimately, for data analysis Pearson's correlation coefficient and regression analysis were used with the help of SPSS software. Results obtained showed that all three variables of identification of the kind of conflict, management of severity of conflict and management of duration of conflict are effective on performance of employees at the Bank of Industry and Mining, Tehran.
\end{abstract}

Keywords: Conflict Management, Performance of Personnel, Bank of Industry and Mining

\section{Introduction}

Firms are social organizations that similar to other organizations are formed of individuals where the main role is placed under the auspices of their directors. In other words, organizations without humans can by no means succeed over and confront problems and on the other hand realize their goals. Undoubtedly, in organizations individuals exist who compete for acquisition of power and interests among each other and contradictions exist with regards to their priorities when it comes to matters and goals. In fact, differences and disputes are necessary for sustenance of organizations so they can adapt themselves with their external environment. The Bank of Industry and Mining like any educational institute with consideration of its budget, material facilities, educational atmosphere, characteristics and needs of students, traits and abilities of employees, rotation of work and administrative trend for educational programs requires special management. The reason is that now a day one of the fundamental issues of organizational management is facing with differences, conflicts and organizational disputes and conflict management is one of the most difficult and at the same time most important duties of each director. One of the main obstacles in the way of realization of an organization's objectives is presence of conflict between individuals. Conflict is considered to be an unavoidable component of organization life which frequently occurs due to organizational specificities (Shiri, 2001, Ghafourian and Falamarzi, 2010).

Conflict is unavoidable and arises because of different goals and opinions and should be directed and minimized. The ability to control conflict undoubtedly is among the most important skills that individuals need. Research in the past regarding higher up and middle standing directors show that a supervisor on the average spends twenty percent of his or her time on conflict resolution. Conflict management because of its importance being higher than decision making skills, leadership and relations, organizations and individuals can enhance their effectiveness by way of conflict management (Abbasi et al, 2009).

Disputes or conflicts are phenomenon with positive and negative influence on performance of individuals and organizations. Conflicts are a natural and normal part of everyday life and are a reality that humanity has been familiar with in history. Yet, unfortunately due to inappropriate management, it has turned into hostility and animosity. Now a day, many of the human resources and regular management systems do not appear ideal and old models are considered inefficient. The phenomenon of complexity of environments in today's era has led organizations to respond in very 
different and varying ways. A firm is a social organization which has a purpose and a system and due to having a structure performs special activities with awareness and has known boundaries. An organization without humans has no power to overcome and encounter difficulties and on the other hand realize its goals. Undoubtedly, in organizations individuals are present that for acquisition of power and interests compete with each other and conflicts exist among their prioritized affairs and objectives. In fact, when there is no coordination and agreement between individual and organizational needs and no matter how individuals endeavor, to gain increased benefits and rights, with taking away the interests and rights of others, conflict arises.

In the past, it was presumed that differences and conflicts lead to disruption of the organization and decrease in the value and credibility of the management. In subsequent research and studies, it was shown that existence of difference and conflict is not necessarily harmful and risky. If a director is able to take advantage of forces, differences in opinions and diversities present using appropriate management such differences may lead to individual and organizational growth. Therefore, correct and effective use of conflict leads to improved performance and promotion of the level of health of an organization and ineffective use can lead to decreased performance and creation of upheaval and disarray in the organization. Effective use of conflict requires complete knowledge and understanding of its nature as well as its causes and acquisition of skill in managing and controlling it which is now a day considered one of the most important skills of management. The ability to encounter conflict and its management has valuable role in the success of directors of firms. If conflicts are productive, they will lead to new and creative ideas and provide the context for change, innovation and productive evolution in the organization and ultimately will help management reach its organizational objectives.

\section{Theoretical Principles}

\subsection{Performance}

Performance refers to the activities of a staff member in executing his or her delegated duties after a specified amount of time. Performance standards involve conditions where a task is performed at an acceptable level quantitatively and qualitatively. Additionally, by evaluating performance, we mean a process by which employees are evaluated at specified time intervals and officially. Acknowledging strong personnel and rewarding them creates motivation for them and other staff to improve their performance and is among the main reasons for evaluating performance. In the past, classic directors evaluated performance just for control of staff duties. Yet, now a day, the guiding and recommending aspects of this action has gained increased importance. The main purpose of evaluating performance is to collect necessary information about forces occupied in an organization and put them in the access of directors so they can make appropriate and needed decisions that will increase quantity and quality of work of staff (Robbins, 2009).

\subsection{Conflict}

Conceptual definition: in the Persian lexicon, conflict means disagreeing with and causing each other inconvenience, engaging in dispute and differing from each other. In a definition, Robbins states that: "Conflict is a process in which, person A deliberately tries in a prohibiting manner to lead to a person's failure in reaching his or her interests and goals» (Robbins, 2009).

Operational definition: Conflict is a natural and normal component of our day to day life and is a reality familiar to humanity along history. Conflict arises when there is lack of coordination and agreement between individual and organization's needs (Robbins, SP, 2000).

\subsection{Conflict Management}

Robbins considers conflict management when a director can in conditions where disagreement exists, manage the organization in the best form and create balance between the organization and members (Robbins, SP, 2000, cited in Afshar et al, 2011). Therefore, what is meant by conflict management is managing at times of conflict and it is believed that conflict is a valuable source of freed human energy that the director can use for revisions in the direction of growth of individuals in the organization. For example, difference in opinion between professors and students of a college can be a factor leading to growth, creativity and innovation and the director can use these differences in the direction of blossoming individuals' talents with the purpose of increased effectiveness (Abbasi, 2009). 


\subsubsection{Conflict of duty}

This kind of conflict means lack of agreement between staff in one occupational unit regarding method and time of performing a duty (Farahbod et al, 2010).

\subsubsection{Procedural conflict}

This kind of conflict means difference of opinion of colleagues regarding the way of performing a duty, changing responsibilities and decision making regarding the method of implementation of law and ... (the same).

\subsubsection{Relational conflict}

This conflict is related to difference of opinion and disagreement between individuals based on personal and social ideas (the same).

Degree of Conflict

Researchers consider conflict severe when it leads to absenteeism from work or displacement and ... and when it has negative effect on individuals' future relationship (Farahbod et al, 2010).

\subsubsection{Length of conflict}

Researchers consider this kind of conflict dangerous for the organization when it leads to sleepiness and fatigue in the work place.

\subsubsection{Sources of conflict}

Factors creating conflict in organizations are numerous and in the following we will refer to some of them:

1. Duty conflicts: means difference of opinion or lack of agreement between members of a group of work unit regarding method and time of performing a duty (Farahbod et al, 2010).

2. Deficiency in the communication system of organizations: an important message may not be received or the orders of a supervisor might be interpreted wrongly and decision makers may reach different conclusions and this issue leads to conflict in the organization.

3. Positional conflict: while organizational roles have great importance, ranking these roles based on their value and significance and creation of a pyramidal form of management leads to creation of positional conflict. Individuals in an organization frequently wish advancement of position to achieve higher income and more important titles (Jahandideh, 2005).

4. Personal differences and lack of adaptation: lack of similarity of individuals with each other and taste and behavioral differences may lead to conflict.

5. Competition for reward: due to limitation in rewards, individuals for being promoted, progressing and achieving organizational emblems and ranks compete with each other. This issue is among potential sources of conflict in the organization.

6. Tension between strategists and specialists: strategies generally have a holistic outlook, yet, specialists tend to details. Various outlooks by these two groups may lead to conflict.

7. Environmental stresses: a stressful and full of tension environment will surely lead to conflict.

\section{Research Hypotheses}

Main hypothesis: conflict management has meaningful correlation with improved performance of personnel.

Minor hypotheses:

1- Apparently identification of the kind of conflict and its management has meaningful correlation with improved performance of personnel.

2- Apparently management of degree of conflict has meaningful correlation with performance of personnel.

3- Apparently management of duration of conflict has meaningful correlation with improved performance of personnel. 


\section{Method}

This research was descriptive and correlational and in this study, the researcher evaluated the relationship between variables of the research by way of a questionnaire. The purpose of this research was identification of the level of use of the three conflict management styles of directors of the Bank of Industry and Mining and its effect on improvement of performance of their employees. In this research, data collection was performed using questionnaire. For this purpose, after study and investigation of the research literature, based on the information about conflict management and conflict management styles in management and organizational behavior texts, questionnaire was designed where its Cronbach's alpha level was 0/85. Therefore, the reliability of the questionnaire was confirmed. Statistical population in this research consisted of 350 active directors in branches of the Bank of Industry and Mining, Tehran. With consideration of the expansiveness and distribution of the population under evaluation, regional random sampling was used so the sample could be selected randomly and logically. Sample size was determined using the Morgan table to be 100 individuals. For data analysis, descriptive statistics (tables, diagrams) and inferential statistics (Pearson's correlation coefficient and regression analysis)were used and all statistical operations were performed using SPSS software.

\section{Results}

\subsection{Descriptive results}

Number of participants based on gender from the findings in Table (1) shows that 80 percent were men and 20 percent women. Additionally, highest percentage of respondents namely 15 percent were in the age group of below 35 years and between 36 and 45 and the least number namely 10 percent belonged to the age range of higher than 56 years.

Table (1). Distribution based on gender and age

\begin{tabular}{|c|c|c|c|}
\hline Variable & Situation & Number & Percentage \\
\hline \multirow{3}{*}{ Gender } & Women & 20 & 20 \\
\cline { 2 - 4 } & Men & 80 & 80 \\
\cline { 2 - 4 } & Total & 100 & 100 \\
\hline \multirow{3}{*}{ Age } & Below 35 years old & 15 & 15 \\
\cline { 2 - 4 } & 36 to 45 years old & 55 & 55 \\
\cline { 2 - 4 } & 46 to 55 years old & 20 & 20 \\
\cline { 2 - 4 } & Total & 100 & 100 \\
\hline
\end{tabular}

\section{Inferential Findings of the Research}

\subsection{Test of first hypothesis}

Apparently identification of the kind of conflict and its management has meaningful correlation with employee performance.

Considering Table (2) regarding the relationship between identification of the kind of conflict and its management with improved performance of personnel, the Pearson statistics (0/277) and the level of error obtained was less than 0/01. Therefore, it can be stated that the relationship between the mentioned variables is meaningful at a 0/99 confidence level and meaningful and direct correlation exists between identification of kind of conflict and its management with improvement in performance of personnel.

\subsection{Test of second hypothesis}

Apparently management of degree of conflict has meaningful correlation with performance of personnel.

Considering Table (2) regarding the relationship between identification of the level of conflict and its management with improved performance of personnel, the Pearson statistics (0/483) and the level of error obtained was less than 0/01. Therefore, it can be stated that the relationship between the mentioned variables is meaningful at a 0/99 confidence level and meaningful and direct correlation exists between identification of level of conflict and its management with improvement in performance of personnel. 


\subsection{Test of third hypothesis}

Apparently management of duration of conflict has meaningful correlation with improved performance of personnel.

Considering Table (2) regarding the relationship between management of duration of conflict with improved performance of personnel, the Pearson statistics (0/485) and the level of error obtained was less than 0/01. Therefore, it can be stated that the relationship between the mentioned variables is meaningful at a 0/99 confidence level and meaningful and direct correlation exists between management of duration of conflict with improvement in performance of personnel.

Table (2). Pearson's correlation coefficient for research variables

\begin{tabular}{|c|c|c|c|}
\hline Variable & \begin{tabular}{|l} 
Pearson's \\
statistics \\
\end{tabular} & \begin{tabular}{|c|} 
P- \\
Value
\end{tabular} & Total \\
\hline Correlation between identification of kind of conflict and its management with improved performance of personnel & $0 / 277$ & $0 / 000$ & 100 \\
\hline Correlation between identification of degree of conflict and its management with improved performance of personnel & 0/483 & $0 / 000$ & 100 \\
\hline Correlation between management of duration of conflict with improved performance of personnel & $0 / 485$ & $0 / 000$ & 100 \\
\hline
\end{tabular}

\section{Regression Analysis}

To evaluate the effect of independent variables on improved performance of personnel of the Bank of Industry and Mining, regression analysis was used.

In the regression model, all considered variables were entered into the model together without specific order or special blocking and were analyzed.

Table (3). $R^{2}$ value for research variables

\begin{tabular}{|c|c|c|c|}
\hline Regression & Correlation & Determination coefficient & Net determination coefficient \\
\hline enter & $0 / 501$ & $0 / 257$ & $0 / 25$ \\
\hline
\end{tabular}

The above table refers to the relationship between independent variables and performance of employees. In this table, the simple correlation coefficient of independent variables with performance of personnel at the Bank of Industry and Mining was equal to 0/501. Explanation coefficient (effect and predicting) of independent variables was almost equal to 0/257 and the moderated explanation coefficient which varies based on degrees of freedom was equal to 0/25.

Table (4). ANOVA table

\begin{tabular}{|c|c|c|c|c|c|}
\hline Age & Sum of squares & Degrees of freedom & Mean squares & $\mathrm{F}$ & Sig \\
\hline Regression & $260 / 458$ & 1 & $65 / 864$ & $127 / 267$ & $0 / 000$ \\
\hline Remainder & $194 / 376$ & 99 & $5 / 122$ & & \\
\hline Total & $454 / 834$ & 100 & & & \\
\hline
\end{tabular}

Table (5): Regression coefficients

\begin{tabular}{|l|c|c|c|c|c|}
\hline Variables & $\mathrm{B}$ & Standard error & Beta & $\mathrm{t}$ & Significance level \\
\hline (constant) & $0 / 198$ & $0 / 538$ & & $0 / 368$ & $0 / 713$ \\
\hline Identification of kind of conflict & $0 / 200$ & $0 / 048$ & $0 / 352$ & $6 / 453$ & $0 / 000$ \\
\hline Management of degree of conflict & $0 / 248$ & $0 / 025$ & $0 / 412$ & $7 / 169$ & $0 / 000$ \\
\hline Management of duration of conflict & $0 / 205$ & $0 / 057$ & $0 / 306$ & $6 / 222$ & $0 / 000$ \\
\hline
\end{tabular}

For determination of the multivariable effects of the independent variables on performance of personnel, multivariable linear regression analysis was used. With consideration of the results of the above table, it can be stated that with one unit increase in the independent variable, the dependent variable increases by the level of the beta coefficient indicated. Considering the results of the table, as noted, the effect of all independent variables on performance of personnel with significance level less than 0/05 shows meaningfulness of all research hypotheses. 


\section{Discussion}

Now a day, human resources as the most fundamental asset of organizations is considered a competitive advantage. Existence of cooperation and cohesiveness in this valuable resource is among the most important factors of success for all organizations. Overall, official nature and objectivity of organizations is identified by their human resources and giving importance to human resources is the basis and axis of management of institutes. One of the factors of efficiency and efficacy of every organization is development and enhancement of the level of performance of its human forces such that having the best personnel and human resources are considered important for advancing organizational goals and helps profitability in the firm. Numerous factors influence efficiency of individuals in the organization and among them, disagreement and conflict between personnel is among important factors that plays role in weakening performance of employees. Undoubtedly, emergence of conflict in organizations and among individuals who are occupied side by side with each other is an unavoidable issue. The work environment of the Bank of Industry and Mining is also similar. The basic characteristic of these kinds of firms which makes evaluation of conflict in them a necessity is their sensitivity and special place and role played in the context of education and research in the Bank of Industry and Mining. Therefore, in this research, we evaluated the influence of conflict management on improvement of performance of personnel at the Bank of Industry and Mining. The results of the research showed that management of identification, degree and duration of conflict has positive correlation with improved personnel performance and $25 \%$ of performance of employees is explained by management of identification, degree and duration of conflict. Therefore, directors for resolution of conflicts arising due to factors such as skills, abilities, different personalities, perception, values, do's and don'ts, emotions and communication barriers and cultural differences take appropriate steps with close relations with others and interest and attention to the organization and sense of responsibility towards others and creation of an atmosphere of trust and understanding in the work environment and provision of occupational guidance and skills. For possession of these human skills, directors should be aware of their weak and strong points, have clear ideas and opinions, have self-esteem, trust others, respect other individuals' ideas, values and emotions, understand them, be aware of the effect of their words and actions on others and be able to provide a secure and acceptable environment for attraction of collaboration between others.

\section{References}

[In Persian]

Abbasi, Homayoun; Hamidi, Mehrzad; Khabiri, Mohammad (2009). Evaluation of the relationship between conflict management and perceived effectiveness in physical education universities (public) in Tehran. Research in Sports Sciences, no 23.

Abili, Khodayar; Movafeghi, Hassan (2003). A gateway to modern managerial concepts. Tehran: Shiveh Publications.

Afshar, Ebrahim; Rejaiipour, Saiid; Madani, Azadeh (2011). Evaluation of application of conflict management styles by library directors of universities. Journal of Research in Book Keeping and Information Sciences, no1, year 1, Spring and Summer.

Farahbod, Farzin; Omi Alavi, Cyrus; Najafzadeh, Sadigheh (2010). Place of conflict management and relational openness in promotion of trust in nursing personnel. Guilan University of Medical Sciences Journal, period1, no79, p24-30.

Ghafourian, Homa; Falamarzi, Ameneh (2010). Evaluation of the relationship between conflict and performance of job management of personnel. Journal of Novelties in Industrial, Organizational Psychiatry, year1, no2.

Jahanian, Ramezan (2010). Evaluation of the relationship between emotional intelligence and conflict management in researching directors. Management Journal, year 8, Special Issue, Spring 2011.

Kazempour, Mehrdad (2005). Article on conflict management. Monthly Journal of Management Strategy.

Rezaiian, Ali (2001). Conflict management. Sadegh Journal, University of Imam Sadegh (greetings to him), Tehran.

Robbins, Stephen P (2009). Principles of organizational behavior (Translation: Ali Parsaian and Mohammad Erabi). Tehran: Office of Cultural Research.

Robbins, Stephen P (2008). Principles of organizational behavior (Translation: Ali Parsaian and Mohammad Erabi). Tehran: Office of Cultural Research.

Taheri, Shahnam (2011). Profiting and its analysis in organizations (global profiting management). Tehran: Hestan Publications.

[In Latin]

Rincón , Beyond(2014), the internal dynamics of organizational responses to conflicting institutional demands, EstudiosGerenciales 30 (2014) 376-383.

Elona Hoover a, Marie K. Harder, What lies beneath the surface? The hidden complexities of organizational change for sustainability in higher education, Journal of Cleaner Production 106 (2015) 175e188

$\mathrm{Haq}$,InamUl The Impact of Interpersonal Conflict on Job Outcomes: Mediating Role of Perception of Organizational Politics, Procedia Social and Behavioral Sciences 25 (2011) $287-310$

Robbins, S. p. (2000). Managing Today. U.S.A, prentice HaLL, International.

Stewart R. Conflict Management. 2008 Available from Work Wide: http: //Www.Peace. Aland Ficonflict/ eid. Htm. 